\title{
Survival after maximum effort cytoreductive surgery and platinum-based chemotherapy in patients with epithelial ovarian cancer, fallopian tube carcinoma and primary peritoneal carcinomatosis: Experience of a Public University Hospital in Spain
}

\author{
Parham Khosravi-Shahi*, Luis Cabezón-Gutiérrez and Sara Custodio-Cabello \\ Department of Medical Oncology, Hospital Universitario de Torrejón, Torrejón de Ardoz, Madrid, Spain
}

\begin{abstract}
Introduction: Epithelial ovarian cancer (EOC), fallopian tube carcinoma (FTC) and primary peritoneal carcinomatosis (PPC) are associated with poor prognosis, and up to $15 \%$ of cases are hereditary. Cytoreductive surgery (CRS) and platinum-based chemotherapy are the cornerstones of the treatment. Material and methods: We performed a retrospective study of a series of 43 consecutive cases using the Tumor Registry Database of our center, with the objective of determining progression-free survival (PFS) and overall survival (OS) in real life (primary end points); as well as post-progression survival (PPS) and the proportion of patients with germline mutations in genes related to hereditary EOC (secondary end points). Results: In our study, median PFS was 53 months, with a probability of PFS at 1, 3 and 5 years of 84,54 and $40 \%$, respectively. Median OS had not been reached, and the probability of OS at 1, 3 and 5 years was 89, 82 and 64\%, respectively. Median PPS was 60 months, and the probability of 5-year PPS was $43 \%$. A total of 7 patients (16.3\%) had pathogenic germline mutations: three patients (6.9\%) in the BRCA-2 gene; two (4.7\%) in the BRCA-1 gene, one (2.3\%) in the ATM gene and another in the MUTYH gene (2.3\%). Conclusions: Our study demonstrates the importance of CRS and platinum-based chemotherapy in patients with EOC, FTC and PPC in the clinical practice; and highlights the relevance of genetic counseling in these patients.
\end{abstract}

Key words: Debulking. PARP. Real world data. Prognosis.

Correspondence:

*Parham Khosravi-Shahi

E-mail: drkhosravi@ hotmail.com
Available online: $04-07-2019$ Gac Mex Oncol. 2019;18:13-21 www.gamo-smeo.com 1665-9201/@ 2019 Sociedad Mexicana de Oncología. Published by Permanyer México. This is an Open Access article under the terms of the CC BY-NC-ND license (http://creativecommons.org/licenses/by-nc-nd/4.0/). 


\section{Introduction}

In Spain, ovarian cancer represented the ninth most common cancer in women in 2015, with a total of 3,228 newly diagnosed cases ${ }^{1}$. Epithelial ovarian cancer (EOC), fallopian tube carcinoma (FTC) and primary peritoneal carcinomatosis (PPC) are associated with poor prognosis, since in clinical practice most cases usually are diagnose at advanced stages, since there are no effective population screening methods and initial stages of the disease have nonspecific symptoms ${ }^{2,3}$. Although the majority of OEC, FTC and PPC cases are sporadic, $11-15 \%$ of cases are estimated to be hereditary, mainly due to the presence of germline mutations of high-penetrance genes such as BRCA-1 and $B R C A-2$ (hereditary breast and ovarian cancer syndrome $)^{4,5}$. For this reason, oncology genetic counseling is currently recommended for all patients with non-mucinous OEC, FTC and PPC ${ }^{6,7}$.

The treatment of OEC, FTC and PPC is essentially based on maximal effort cytoreductive surgery (CRS), with the purpose to obtain optimal debulking (CRSO), leaving only residual microscopic disease, in combination with chemotherapy based on platinum salts in cases of high risk of relapse ${ }^{8,9}$. However, in spite of the remarkable advances in the knowledge of molecular biology and the appearance of new systemic oncological treatments (bevacizumab, poly-ADP-ribose-polymerase [PARP] enzyme inhibitors) $)^{10,11}$, ovarian cancer continues to be the leading cause of death due to gynecological cancer and the fifth cause of cancer death in Spanish women ${ }^{12}$. Overall, the prognosis of patients with OEC, FTC and PPC is poor, with a probability of 5 -year overall survival (OS) of $37-47 \% \%^{13}$. OS in these patients decreases as the stage of disease increases at diagnosis according to the International Federation of Gynecology and Obstetrics (FIGO) classification. Five-year OS for patients with localized stages (stages I and II) combined is around $80 \%$, in comparison with advanced stages (stages III and IV), where 5-year OS is only $10-30 \%{ }^{14}$.

For this reason, we have carried out a study of a series of 43 consecutive cases of patients with OEC, FTC and PPC who have been diagnosed and treated in our center since its opening in October 2011 (using the Hospital Tumor Registry database), with the purpose to determine the prognosis of these patients treated with CRS and/or platinum-based chemotherapy in the real world (real-life data), as well as to know the proportion of patients with germline mutations in genes related to hereditary OEC and its possible correlation with prognostic and clinicopathological characteristics. In our center, an average of 68 patients are newly diagnosed with gynecological tumors every year, with endometrial cancer being the most common gynecological tumor, followed by cervical and ovarian cancer.

\section{Material and methods}

We carried out a retrospective, descriptive, analytical analysis of a series of consecutive cases of patients with OEC, FTC and PPC who have been diagnosed and treated in our center since its opening in October 2011. In this study, all patients with a histopathological diagnosis of OEC, FTC and PPC at any FIGO stage (stages I, II, III and IV) recorded in the Tumor Registry database of our Hospital between October 2011 and October 2017, and who also had been diagnosed and treated (CRS and/or first-line platinum-based chemotherapy treatment) in our center, were included, with the purpose to determine the prognosis of these patients under real conditions, as well as to know the proportion of patients with germline mutations in genes related to hereditary OEC and their possible correlation with clinicopathological characteristics and prognosis. All study patients gave written informed consent for the start of first-line platinum-based chemotherapy treatment and/or CRS, as well as for inclusion in this study. All patients with a histopathological diagnosis other than OEC, FTC and PPC, patients who did not complete the treatment (CRS and/or first-line platinum-based chemotherapy) in our center, or who were lost to follow-up or had a second synchronous or metachronous malignant tumor were excluded from the study.

The present study has been carried out in accordance with the World Health Organization ethical code (Declaration of Helsinki).

\section{Therapeutic strategies}

The study patients were treated in our clinical practice according to one of the following therapeutic strategies, based on a multidisciplinary decision by the Gynecological Tumors Committee of our center:

- If the disease was initially considered resectable, the patients underwent maximal effort primary CRS, followed by platinum-based chemotherapy in cases with clinicopathological criteria of high risk of recurrence (FIGO stage IC or G3, FIGO stage II and FIGO stage III). The different chemotherapy regimens used were: a) carboplatin, area under the curve 6 plus paclitaxel $175 \mathrm{mg} / \mathrm{m}^{2}$ every 21 days (CP), 
intravenously; b) CP plus bevacizumab $15 \mathrm{mg} / \mathrm{kg}$ every 21 days followed by intravenous maintenance bevacizumab up to a maximum of 15 months (CP-B), only in cases with advanced stages (FIGO stages III and IV), and c) capecitabine $1,000 \mathrm{mg} / \mathrm{m}^{2}$ every 12 hours for 14 days orally plus oxaliplatin $130 \mathrm{mg} / \mathrm{m}^{2}$ intravenously every 21 days (CAPEOX), only in cases with a diagnosis of mucinous ovarian carcinoma.

- If the disease was considered unresectable at diagnosis (FIGO stage IIIC with high tumor burden and FIGO stage IV), the patients were treated with preoperative or first-line chemotherapy with the above-described regimens, followed by maximal-effort CRS in cases with radiological response.

\section{Genetic studies}

Patients diagnosed with non-mucinous OEC, FTC and PPC, following current clinical guidelines recommendations, were offered the possibility of genetic counseling in our Oncology Genetic Counseling Unit. All patients who accepted the genetic study gave written informed consent for the test and, subsequently, a peripheral blood sample was obtained (one blood collection tube). Peripheral blood samples were analyzed with a multigene platform by means of massive sequencing technology. This platform includes various genes related to hereditary breast and/or ovarian cancer (BRCA-1, BRCA-2, CHEK2, PALB2, BRIP1, TP53, PTEN, STK11, CDH1, ATM, BARD1, MLH1, MRE11A, MSH2, MSH6, MUTYH, NBN, PMS1, PMS2, RAD50 and $R A D 51 C)$. The genetic sequencing test was carried out using a custom designed NimbleGen capture kit and a Hiseq platform (Illumina) for subsequent sequencing. In general, this platform allows the analysis of more than $95 \%$ of target genes with a sensitivity higher than $99 \%$. This way, point mutations, microinsertions, deletions and duplications ( $<20 \mathrm{bp}$ ) can be simultaneously analyzed.

\section{Statistical analysis and study endpoints}

The primary endpoints of our study were progression-free survival (PFS) and OS analysis in the overall study population, as well as stratified analyses according to different predetermined subgroups: a) FIGO stage (I-II vs. III-IV); b) histological subtype (serous vs. mucinous); c) CRS type (optimal vs. suboptimal), and d) type of primary treatment (primary CRS vs. upfront chemotherapy). PFS and OS in this study were expressed both as medians with $95 \%$ confidence intervals
(CI), and as 1, 3 and 5-year PFS and OS probability. In the study, PFS referred to the period from the date of primary treatment initiation (CRS or chemotherapy) to the date at which any of the following events occurred: progression, death or date of last contact if the patient was still alive and progression-free. OS referred to the period from the date of histopathological diagnosis to the date at which death occurred or the date of last contact if the patient was still alive.

The platinum-free interval (PFI) in the study was defined as the period between the date of the last platinum-based chemotherapy cycle administration and the date of progression. According to PFI, the patients with progression were classified as: a) platinum-refractory (progression during the period of chemotherapy administration); b) platinum-resistant (if PFI was shorter than 6 months); c) intermediate sensitive to platinum (if PFI was 6-12 months), and d) highly sensitive to platinum (if PFI was longer than 12 months).

The secondary endpoints of the study were:

- Post-progression survival (PPS) analysis, defined as the period from the date of progression to the date of death or last contact if the patient was still alive, in the subgroup of patients with disease progression after CRS and/or first-line chemotherapy.

- Germline mutations descriptive analysis in genes related to hereditary OEC found in the study patients and their correlation with prognosis and clinicopathological characteristics.

For statistical analysis of the study, the statistical package SPSS ${ }^{\circledR}$ version 12.0 was used, with the Kaplan and Meier method being used for PFS and OS analysis; for the comparison of the different survival curves, the log-rank test was used.

\section{Results}

Of the 61 patients included in the Tumor Registry database of our center as ovarian tumors between October 2011 and October 2017, a total of 43 consecutive patients diagnosed with OEC, FTC and PPC were finally included in the study for analysis of the primary and secondary endpoints; 18 patients were excluded, as detailed in figure 1.

Baseline clinicopathological characteristics of the patients included in the study are summarized in table 1. Median age of the study patients $(n=43)$ was 59 years (range: 29-82). Of the patients included in the study, $68 \%(n=29)$ had advanced stages (FIGO stages III-IV) at diagnosis, $95 \%$ had OCE, $63 \%$ had high-grade serous carcinoma and $95 \%$ had a good general and 


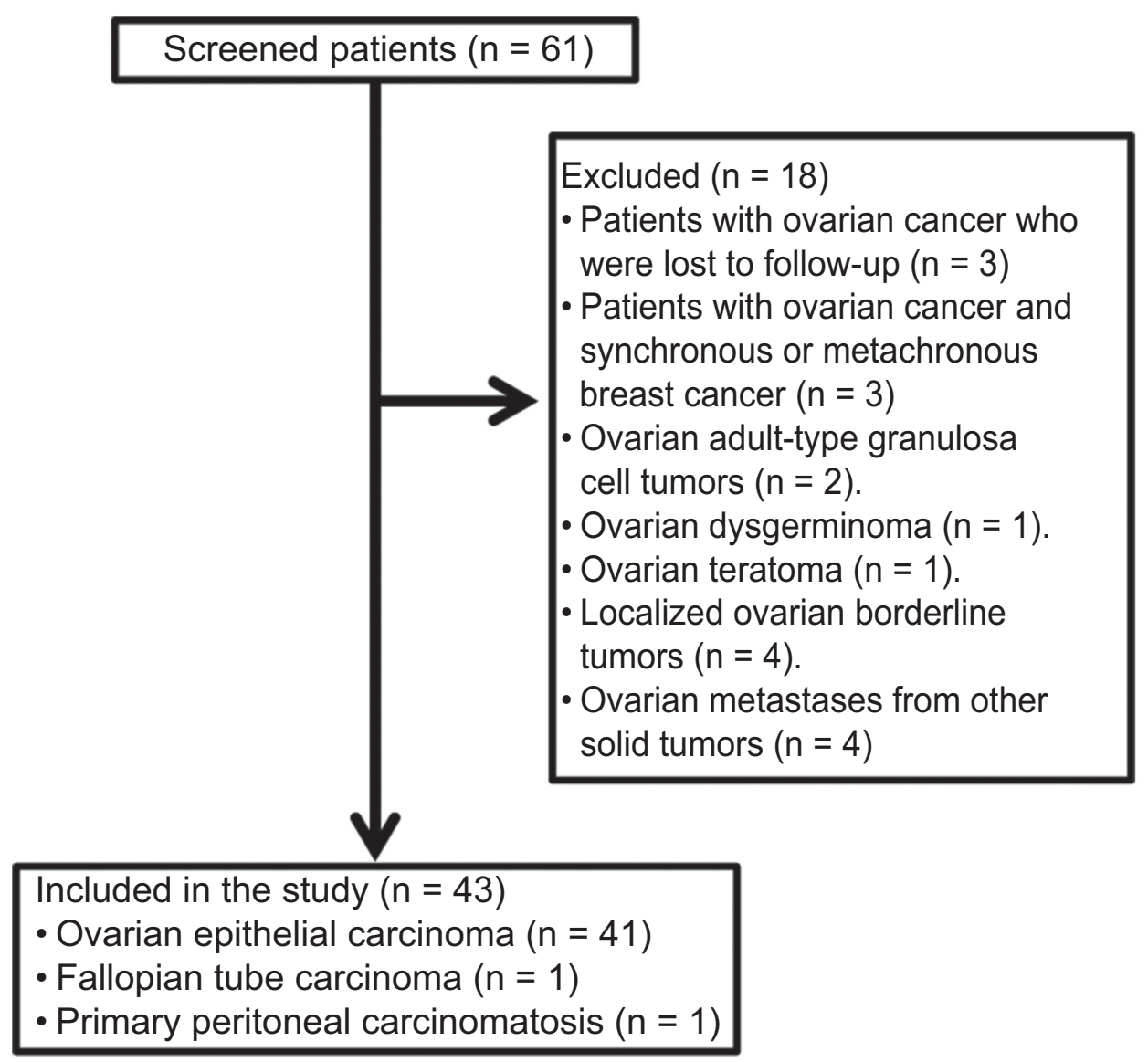

Figure 1. Study patients' flow chart.

functional condition (Performance Status [PS] 0-1). Fifty-eight percent of patients $(n=25)$ were upfront operated as the disease was considered resectable, 35\% underwent interval CRS after chemotherapy and three patients had no CRS at any time during their evolution (all of them with FIGO stage IV). In total, 33 patients included in the study had an optimal CRS (CRSO), 23 patients with upfront and 10 patients with interval CRS. A total of $88 \%$ of patients in the study were treated with platinum-based first-line chemotherapy $(60 \%$ with CP, $23 \%$ with CP-B and $5 \%$ with CAPEOX).

\section{Study primary endpoints}

At study closure in March 2018, there a total of 15 DFS events (15 patients with disease progression) and 8 OS events had occurred (8 deaths due to disease overt progression). With a median follow-up of 36 months (95\% Cl: 27-44) for alive patients, median PFS for the overall study population $(n=43)$ was 53 months (95\% Cl: 16-90), with a probability of 1-year, 3-year and 5-year DFS of 84,54 and $40 \%$, respectively (Fig. 2). Of the 15 disease progression detected cases (34.9\% of overall population), $13 \%(n=2)$ were platinum refractory, $7 \%(n=1)$ were platinum resistant, $20 \%$ $(n=3)$ had intermediate sensitivity to platinum, and the remaining $60 \%(n=9)$ had high sensitivity to platinum. Median OS for the overall set of patients in the study had not been reached, and the probability of 1-, 3-, and 5-year OS was 89, 82, and 64\%, respectively (Fig. 3). Of the eight described deaths ( $18.6 \%$ of overall population), $62.5 \%$ occurred in patients with PFI of less than 12 months $(n=5)$.

Regarding the survival analysis stratified according to pre-specified subgroups, median PFS in patients with localized stages (FIGO stages I-II, $n=14$ ) had not been reached (with only 1 PFS event), while in patients with advanced stages (FIGO stages III-IV, $n=29$ ), it was 27 months (95\% Cl: 9-45), with 14 events having occurred in this subgroup, which accounts for $93.3 \%$ of 
Table 1. Overall study population ( $n=43$ ) baseline clinicopathological characteristics

\begin{tabular}{|c|c|c|}
\hline Variable & $\mathbf{N}$ & Proportion \\
\hline $\begin{array}{l}\text { Age } \\
<60 \text { years } \\
>60 \text { years }\end{array}$ & $\begin{array}{l}25 \\
18\end{array}$ & $\begin{array}{l}58 \% \\
42 \%\end{array}$ \\
\hline $\begin{array}{l}\text { Performance Status (PS) at diagnosis } \\
0 \\
1 \\
2\end{array}$ & $\begin{array}{c}25 \\
16 \\
2\end{array}$ & $\begin{array}{l}58 \% \\
37 \% \\
5 \%\end{array}$ \\
\hline $\begin{array}{l}\text { FIGO stage } \\
\text { IA } \\
\text { IC } \\
\text { IIA } \\
\text { IIIB } \\
\text { IIIC } \\
\text { IV }\end{array}$ & $\begin{array}{c}5 \\
7 \\
2 \\
2 \\
22 \\
5\end{array}$ & $\begin{array}{c}12 \% \\
15 \% \\
5 \% \\
5 \% \\
51 \% \\
12 \%\end{array}$ \\
\hline $\begin{array}{l}\text { Histological subtype } \\
\text { Serous carcinoma } \\
\text { Mucinous carcinoma } \\
\text { Endometrioid carcinoma } \\
\text { Clear cell carcinoma } \\
\text { Mixed }\end{array}$ & $\begin{array}{l}27 \\
7 \\
5 \\
2 \\
2\end{array}$ & $\begin{array}{c}63 \% \\
15 \% \\
12 \% \\
5 \% \\
5 \%\end{array}$ \\
\hline $\begin{array}{l}\text { Primary tumor site } \\
\text { Ovary } \\
\text { Peritoneum } \\
\text { Fallopian tube }\end{array}$ & $\begin{array}{c}41 \\
1 \\
1\end{array}$ & $\begin{array}{l}95 \% \\
2.5 \% \\
2.5 \%\end{array}$ \\
\hline $\begin{array}{l}\text { Histological grade }(\mathrm{G}) \\
\text { G1 } \\
\text { G2 } \\
\text { G3 }\end{array}$ & $\begin{array}{c}6 \\
3 \\
34\end{array}$ & $\begin{array}{l}14 \% \\
7 \% \\
79 \%\end{array}$ \\
\hline $\begin{array}{l}\text { Type of cytoreductive surgery (CRS) } \\
\text { Optimal upfront CRS } \\
\text { Optimal interval CRS } \\
\text { Suboptimal upfront CRS } \\
\text { Suboptimal interval CRS } \\
\text { No CRS }\end{array}$ & $\begin{array}{c}23 \\
10 \\
2 \\
5 \\
3\end{array}$ & $\begin{array}{c}53 \% \\
23 \% \\
5 \% \\
12 \% \\
7 \%\end{array}$ \\
\hline $\begin{array}{l}\text { First received treatment } \\
\text { Surgery } \\
\text { Chemotherapy }\end{array}$ & $\begin{array}{l}25 \\
18\end{array}$ & $\begin{array}{l}58 \% \\
42 \%\end{array}$ \\
\hline $\begin{array}{l}\text { First-line chemotherapy regimen } \\
\text { Capecitabine-oxaliplatin } \\
\text { Carboplatin-paclitaxel-bevacizumab } \\
\text { Carboplatin-paclitaxel } \\
\text { No chemotherapy }\end{array}$ & $\begin{array}{c}2 \\
10 \\
26 \\
5\end{array}$ & $\begin{array}{c}5 \% \\
23 \\
60 \% \\
12 \%\end{array}$ \\
\hline $\begin{array}{l}\text { Family history of cancer } \\
\text { None } \\
\text { Breast cancer } \\
\text { Ovarian cancer } \\
\text { Breast and ovarian cancer }\end{array}$ & $\begin{array}{c}33 \\
5 \\
4 \\
1\end{array}$ & $\begin{array}{l}77 \% \\
12 \% \\
9 \% \\
2 \%\end{array}$ \\
\hline
\end{tabular}

PFS events. The probability of 5-year PFS was $86 \%$ in the subgroup of patients with localized stages and $21 \%$ in the subgroup of patients with advanced stages $(p=0.025)$ (Fig. 4). Median OS had not been reached in neither of both subgroups, and the probability of 5 -year OS was $100 \%$ in the subgroup of patients with localized stages and $57 \%$ in the subgroup of patients with advanced stages $(p=0.094)$. The probability of 5 -year OS was 58\% for patients with FIGO stage III and $50 \%$ for patients with FIGO IV stages ( $p=0.488$ ).

Regarding the histological subtype, median PFS was 25 months (95\% Cl: 11-39) in the subgroup of patients with mucinous carcinoma and 27 months (95\% Cl: 10-44) in the subgroup of patients with serous carcinoma. The probability of 5-year PFS was $33 \%$ in the subgroup with mucinous carcinoma and $41 \%$ in the subgroup with serous carcinoma $(p=0.149)$. The probability of 5 -year OS was $67 \%$ for the subgroup of patients with mucinous carcinoma and $56 \%$ for the subgroup of patients with serous carcinoma $(p=0.351)$. Median OS had not been reached in either of both subgroups.

In the subgroup of patients who underwent optimal CRS, the PFS median had not been reached, whereas in the subgroup of patients with suboptimal CRS (with gross residual disease) it was 11 months (95\% Cl: 4-18). The probability of 5 -year PFS was $55 \%$ in the subgroup with optimal CRS, in comparison with a PFS probability of $0 \%$ in the subgroup of patients with suboptimal CRS $(p<0.0001)$. The probability of 5 -year OS was $86 \%$ in the subgroup with optimal CRS and $17 \%$ in the subgroup with suboptimal CRS $(p<0.0001)$; median OS had not been reached in the optimal CRS subgroup and it was 18 months (95\% Cl: 1-35) in the subgroup with suboptimal CRS.

Finally, regarding the type of primary treatment, in the subgroup of patients treated with upfront CRS ( $n=25,58 \%$ of total population), the probability of 5 -year PFS was 57\%, in comparison with a probability of $24 \%$ in the subgroup of patients treated with chemotherapy as first treatment $(p=0.008)$. Median PFS had not been reached in the first group, and it was 25 months (95\% Cl: 17-33) for the second subgroup. The probability of 5 -year OS was $89 \%$ in the subgroup of patients treated with upfront CRS versus $44 \%$ in the subgroup of patients treated with neoadjuvant chemotherapy ( $p=0.097$ ), with median OS not reached in the first subgroup and of 60 months (95\% Cl: $12-108)$ in the second subgroup.

\section{Study secondary endpoints}

In the subgroup of patients with disease progression after CRS and/or first-line chemotherapy $(n=15)$, median PPS was 60 months (95\% Cl: 10-124) and the probability of 5 -year PPS was $43 \%$. In patients with platinum-sensitive disease, median PPS was 60 months, in comparison with a median PPS of 7 months in 


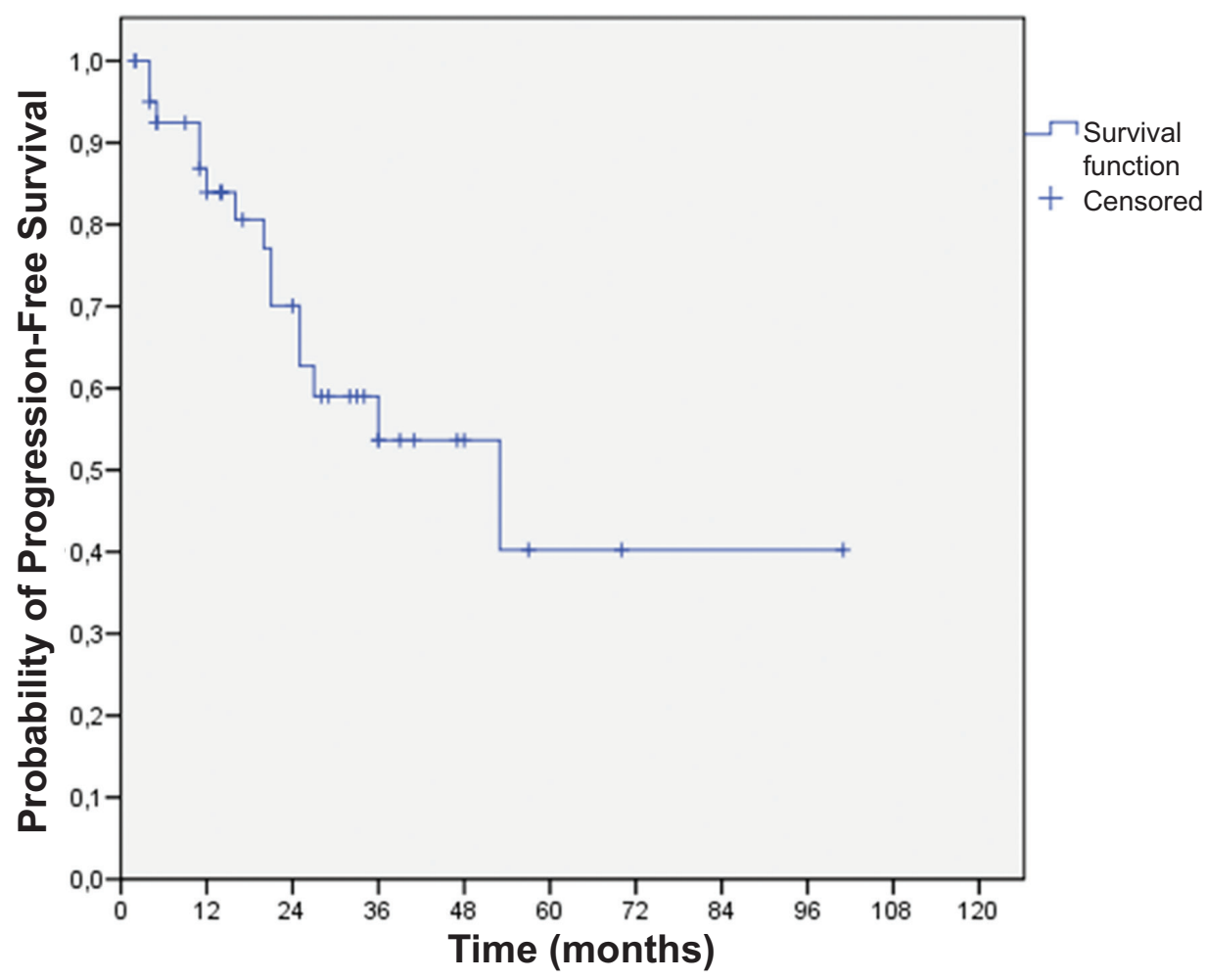

Figure 2. Disease progression-free survival curve in the overall study population $(n=43)$.

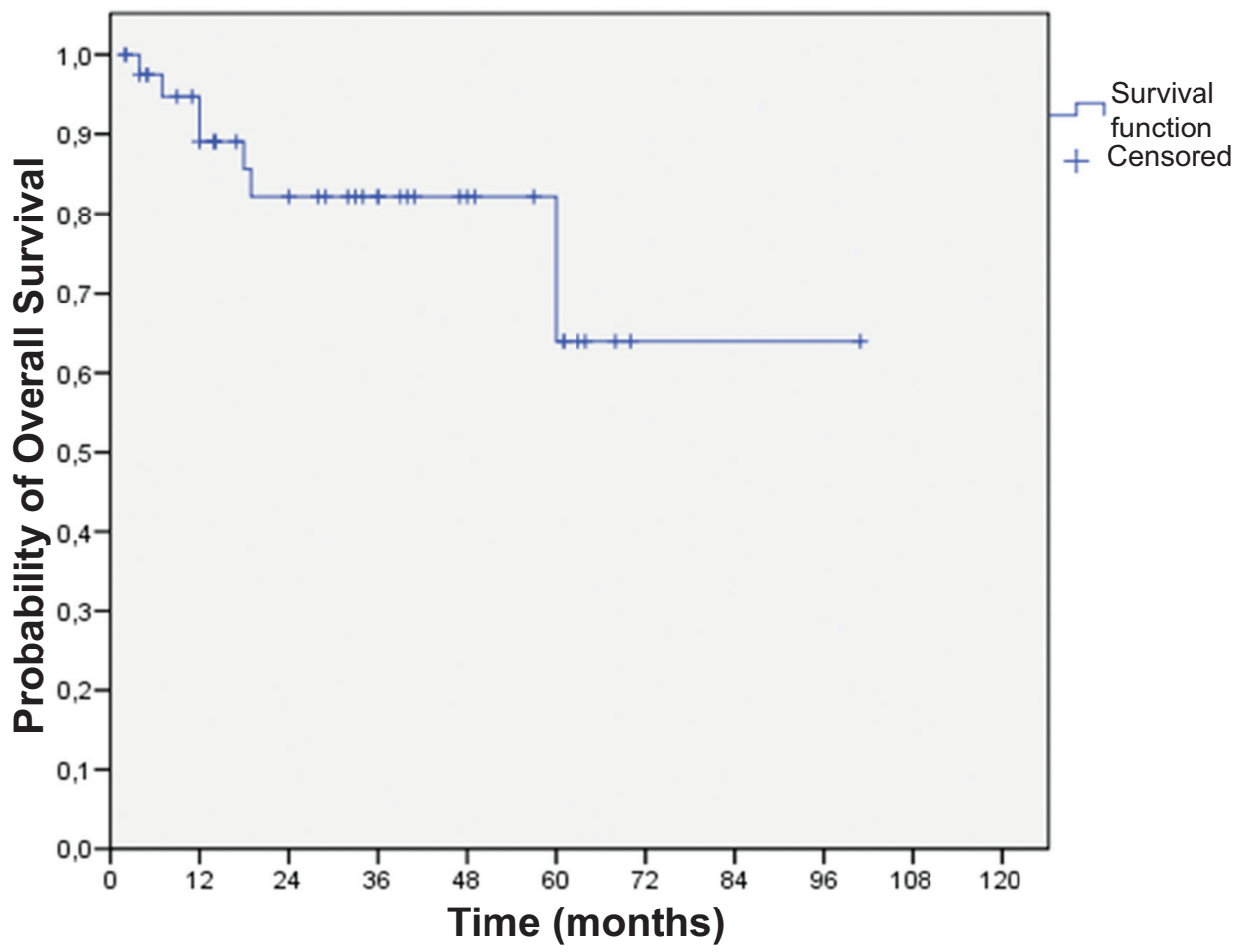

Figure 3. Overall survival curve in total study population $(n=43)$. 


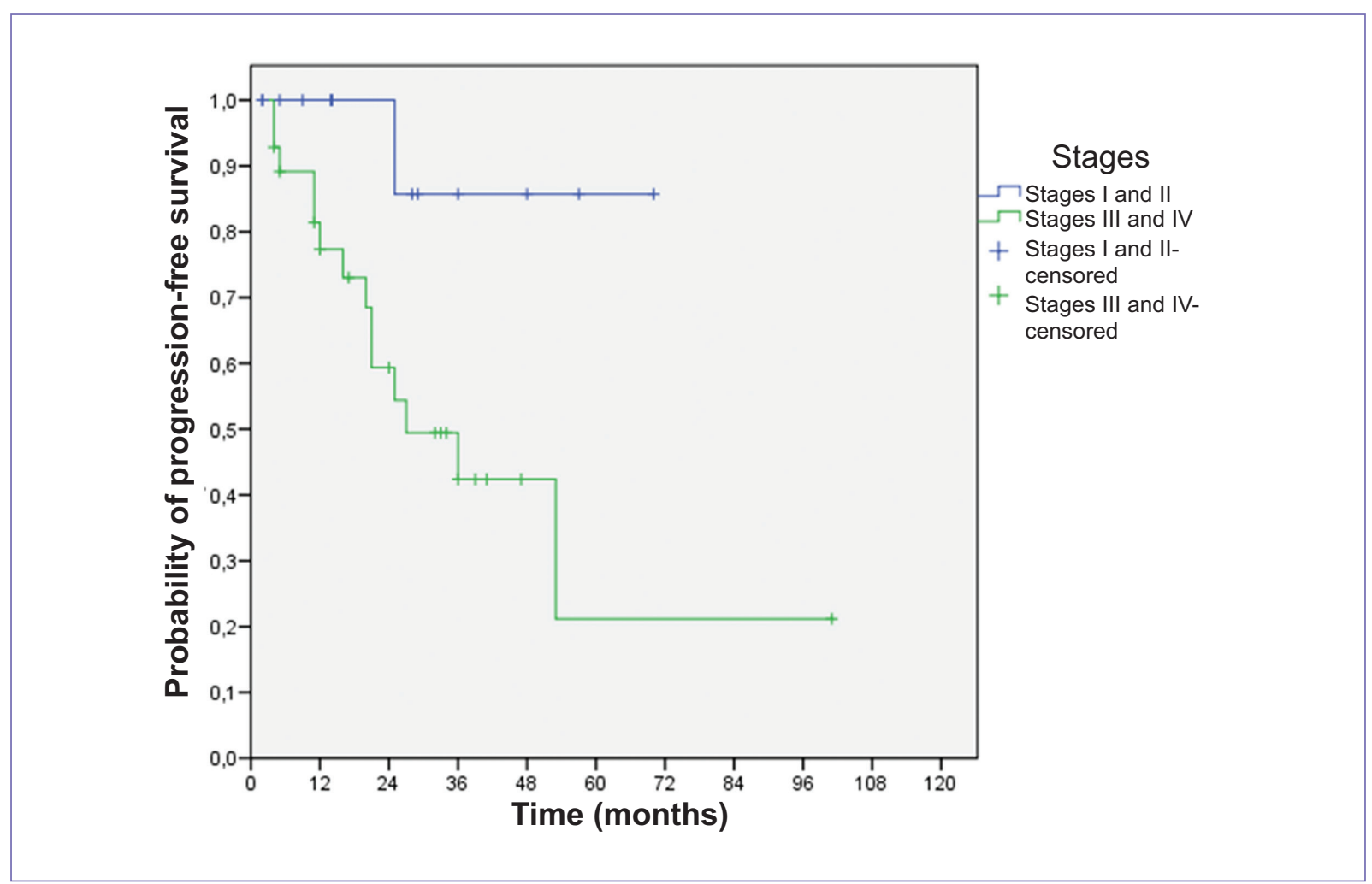

Figure 4. Disease progression-free survival curves by stage (FIGO stages I-II and III-IV).

patients with platinum-refractory/resistant disease, and the probability of 1 -year PPS was 90 and $25 \%$, respectively $(p=0.033)$. Median treatment lines received after disease progression was four (range: 1-6).

In the study, a total of seven patients $(16.3 \%$ of total population) had pathogenic germline mutations in genes related to hereditary OEC. Three patients $(6.9 \%$ of total population) had pathogenic mutations in the BRCA-2 gene: one case with the c.4859insA (p.NI$544 \mathrm{fs})$ mutation, one case with the c.1313_1314insT mutation and another case with the c.1587delTinsCA mutation. Two patients (4.7\% of total population) had pathogenic mutations in the BRCA-1 gene (one case with the EX1_17 DEL mutation and another case with the p.Pro1812Ala mutation), one patient had a pathogenic mutation in the ATM gene (p.GIn501Ter) and another in the MUTYH gene (p.Tyr179Cys). Baseline clinicopathological characteristics of this subgroup of patients and their comparison with the subgroup of patients without mutations are described in table 2.

In the subgroup of patients with germline mutations, median PFS was 27 months (95\% Cl: 24-30), in comparison with a median PFS of 53 months (95\% Cl: $19-87)$ in the subgroup of patients without germline mutations; and the probability of 5-year DFS was 28 and $43 \%$, respectively ( $p=0.53$ ). Median OS was 60 months (95\% Cl: 10-128) for the subgroup of patients with germline mutations and it had not been reached in the subgroup of patients without mutations; the probability of 5 -year OS was 42 and $71 \%$, respectively $(p=0.596)$.

\section{Discussion}

The results of our study highlight the importance of optimal CRS in combination with platinum-based first-line chemotherapy, as well as the relevance of oncology genetic counseling in patients with OEC, FTC and PPC in routine clinical practice.

The survival results obtained in the overall population of our study (real-life data) are highly encouraging; they are superior to data published by other authors in real-life settings and in clinical trials (under ideal conditions with stricter patient selection). In the overall population of our study, the probability of 5-year OS was $64 \%$, while in the study carried out by Siegel, et al. it was $47 \%{ }^{13}$ and, in the ICON-7 study, it was $50 \%{ }^{10}$. In the present study, the prognosis of patients with OEC, 
Table 2. Baseline clinicopathological characteristics of patients with germline mutations in genes related to hereditary ovarian cancer and their comparison with the population not bearing germline mutations

\begin{tabular}{|c|c|c|}
\hline Variable & $\begin{array}{l}\text { With mutation } \\
\qquad(n=7)\end{array}$ & $\begin{array}{l}\text { Without mutation } \\
\qquad(\mathrm{n}=36)\end{array}$ \\
\hline $\begin{array}{l}\text { Age } \\
\text { Median } \\
\text { Range }\end{array}$ & $\begin{array}{c}60 \\
43-82\end{array}$ & $\begin{array}{c}56 \\
29-78\end{array}$ \\
\hline $\begin{array}{l}\text { Performance status (PS) } \\
\text { at diagnosis } \\
1 \\
2 \\
3\end{array}$ & $\begin{array}{l}4(57 \%) \\
3(43 \%) \\
\quad 0\end{array}$ & $\begin{array}{c}21(58 \%) \\
13(36 \%) \\
2(6 \%)\end{array}$ \\
\hline $\begin{array}{l}\text { FIGO stage } \\
\text { IA } \\
\text { IC } \\
\text { IIA } \\
\text { IIIB } \\
\text { IIIC } \\
\text { IV }\end{array}$ & $\begin{array}{c}1(14 \%) \\
0 \\
0 \\
0 \\
4(57 \%) \\
2(29 \%)\end{array}$ & $\begin{array}{c}4(11 \%) \\
7(19 \%) \\
2(6 \%) \\
2(6 \%) \\
18(50 \%) \\
3(8 \%)\end{array}$ \\
\hline $\begin{array}{l}\text { Histological subtype } \\
\text { Serous carcinoma } \\
\text { Mucinous carcinoma } \\
\text { Endometrioid } \\
\text { carcinoma } \\
\text { Clear cell carcinoma } \\
\text { Mixed }\end{array}$ & $\begin{array}{c}7(100 \%) \\
0 \\
0 \\
\\
0 \\
0\end{array}$ & $\begin{array}{l}20(56 \%) \\
7(19 \%) \\
5(14 \%) \\
2(6 \%) \\
2(6 \%)\end{array}$ \\
\hline $\begin{array}{l}\text { Primary tumor site } \\
\text { Ovary } \\
\text { Peritoneum } \\
\text { Fallopian tube }\end{array}$ & $\begin{array}{l}5(72 \%) \\
1(14 \%) \\
1(14 \%)\end{array}$ & $\begin{array}{c}36(100 \%) \\
0 \\
0\end{array}$ \\
\hline $\begin{array}{l}\text { Histological grade } \\
\text { G1 } \\
\text { G2 } \\
\text { G3 }\end{array}$ & $\begin{array}{c}0 \\
0 \\
7(100 \%)\end{array}$ & $\begin{array}{c}6(17 \%) \\
3(8 \%) \\
27(75 \%)\end{array}$ \\
\hline $\begin{array}{l}\text { Type of cytoreductive } \\
\text { surgery (CRS) } \\
\text { Optimal upfront CRS } \\
\text { Optimal interval CRS } \\
\text { Suboptimal upfront CRS } \\
\text { Suboptimal interval CRS } \\
\text { No CRS }\end{array}$ & $\begin{array}{c}2(29 \%) \\
2(29 \%) \\
0 \\
1(14 \%) \\
2(29 \%)\end{array}$ & $\begin{array}{c}21(58 \%) \\
8(22 \%) \\
2(6 \%) \\
4(11 \%) \\
1(3 \%)\end{array}$ \\
\hline $\begin{array}{l}\text { First treatment received } \\
\text { Surgery } \\
\text { Chemotherapy }\end{array}$ & $\begin{array}{l}2(29 \%) \\
5(71 \%)\end{array}$ & $\begin{array}{l}23(64 \%) \\
13(36 \%)\end{array}$ \\
\hline $\begin{array}{l}\text { Family history of cancer } \\
\text { None } \\
\text { Breast cancer } \\
\text { Ovarian cancer } \\
\text { Breast and ovarian } \\
\text { cancer }\end{array}$ & $\begin{array}{c}1(14 \%) \\
3(43 \%) \\
3(43 \%) \\
0\end{array}$ & $\begin{array}{c}32(88 \%) \\
2(6 \%) \\
1(3 \%) \\
1(3 \%)\end{array}$ \\
\hline
\end{tabular}

FTC and PPC was essentially marked by the disease stage at diagnosis (worse prognosis in FIGO stages III and IV), the type of CRS (lower survival in cases with suboptimal CRS) and the type of first treatment received (poorer prognosis in patients treated with neoadjuvant chemotherapy). The probability of 5-year PFS was significantly higher in patients with localized stages, in comparison with patients with advanced stages, with an absolute difference of $65 \%$ ( $86 \%$ vs. $21 \%$, respectively, $p=0.025)$. There was also a nonsignificant trend towards longer OS in patients with localized disease, with an absolute difference of $43 \%$ in 5 -year OS (100 vs. $57 \%$, respectively, $p=0.094$ ). OS in patients with advanced stages in our study was superior to those described in the literature, with the probability of 5-year OS being $58 \%$ for patients with FIGO III stage and $50 \%$ for patients with FIGO IV stages. Patients treated with optimal CRS had significantly higher PFS and OS in comparison with patients treated with suboptimal CRS (55\% 5-year PFS with optimal CRS vs. 0\% with suboptimal CRS, $p<0.0001 ; 5$-year OS of 86 vs. $17 \%$, respectively, $p<0.0001$ ). Median OS in patients treated with suboptimal CRS was only 18 months. There is a large body of scientific evidence that supports the performance of a maximal effort CRS in order to reach residual microscopic disease, since this is the most relevant prognostic factor ${ }^{15,16}$, as it also was demonstrated in our study. On the other hand, PFS was significantly higher in patients treated with upfront CRS, in comparison with patients treated with neoadjuvant chemotherapy, with an absolute difference of $33 \%$ at 5 years (5-year PFS of 57 vs. $24 \% ; p=0.008$ ). There was also a nonsignificant trend towards higher OS rates in patients treated with upfront CRS (5-year OS of 89 vs. $44 \%, p=0.097$ ). Therefore, in our study, as in other studies published to date, upfront CRS was associated with a better prognosis in comparison with interval CRS after neoadjuvant chemotherapy ${ }^{17,18}$.

Our study also highlights the relevance of the oncological treatments received at disease progression, especially in patients with PFIs longer than 6 months (platinum-sensitive). In patients with disease progression, median PPS was 60 months, and the probability of 5-year PPS was $43 \%$. In patients with platinum-sensitive disease, PPS was significantly longer (60-month median for $\mathrm{PFI} \geq 6$ months vs. 7 months for $\mathrm{PFI}$ $<6$ months, $\mathrm{p}=0.033$ ).

Finally, this study highlights the importance of genetic counseling for patients with OEC, FTC and PPC and their relatives. In this sense, $16.3 \%$ of patients in the study had germline mutations in genes related to hereditary OEC, out of which $71.4 \%$ were in the BRCA-1 and $B R C A-2$ genes. Genetic counseling is of vital importance for these patients and their families, given that, on one hand, the presence of these genetic 
mutations increases the sensitivity to platinum salts (cisplatin and carboplatin) and to PARP inhibitors (olaparib, rucaparib, niraparib) ${ }^{19,20}$ and, on the other hand, it is associated with a $50 \%$ risk of hereditary transmission to the offspring, with a consequent increase in the risk of breast and ovarian cancer in the family. In this subgroup of patients, the dominant histology was high-grade serous carcinoma, and the majority of cases $(86 \%)$ were diagnosed at advanced stages (III and IV). Nevertheless, prognosis of these patients was similar to that of patients without genetic mutations.

\section{Conclusion}

In conclusion, our study demonstrates the importance of optimal upfront CRS, in combination with platinum-based first-line chemotherapy, in patients with OEC, FTC and PPC in routine clinical practice; and, in addition, it highlights the relevance of oncology genetic counseling in these patients. We recommend performing the study of germline mutations in genes involved in non-mucinous OEC oncogenesis (such as BRCA-1, BRCA-2, CHEK2, PALB2, BRIP1, TP53, PTEN, STK11, CDH1, ATM, BARD1, MLH1, MRE11A, MSH2, MSH6, MUTYH, NBN, PMS1, PMS2, RAD50 and RAD51C) with the use of multigene platforms (massive sequencing technology NGS), given the high prevalence of such mutations in these patients.

\section{Funding}

The present investigation has not received specific grants from agencies of the public sector, commercial sector or non-profit entities.

\section{Conflict of interests}

The authors declare not having any conflicts of interest.

\section{Ethical responsibilities}

Protection of people and animals. The authors declare that no experiments have been carried out on humans or animals for this research.
Confidentiality of data. The authors declare having followed the protocols of their work center on the publication of patient data.

Right to privacy and informed consent. The authors declare that no patient data appear in this article.

\section{References}

1. Galceran J, Ameijide A, Carulla M, Mateos A, Quirós JR, Rojas D, et al. Cancer incidence in Spain, 2015. Clin Transl Oncol. 2017;19:799-825.

2. Menon U, Griffin M, Gentry-Maharaj A. Ovarian cancer screening-current status, future directions. Gynecol Oncol. 2014;132:490-5.

3. Nezhat FR, Apostol R, Nezhat C, Pejovic T. New insights in the pathophysiology of ovarian cancer and implications for screening and prevention. Am J Obstet Gynecol. 2015;213:262-7.

4. Belanger MH, Dolman L, Arcand SL, Shen Z, Chong G, Mes-Masson AM, et al. A targeted analysis identifies a high frequency of BRCA-1 and BRCA-2 mutation carriers in women with ovarian cancer from a founder population. J Ovarian Res. 2015;8:1-3.

5. Mavaddat N, Peock S, Frost D, Ellis S, Platte R, Fineberg E, et al Cancer risks for BRCA-1 and BRCA-2 mutation carriers: results from a prospective analysis of EMBRACE. J Natl Cancer Inst. 2013;105:812-22.

6. Capoluongo E, Ellison G, López-Guerrero JA, Penault-Llorca F, Ligtenberg MJL, Banerjee S, et al. Guidance statement on BRCA-1/2 tumor testing in ovarian cancer patients. Semin Oncol. 2017;44:187-97.

7. Llort G, Chirivella I, Morales R, Serrano R, Sanchez AB, Teulé A, et al. SEOM clinical guidelines in hereditary breast and ovarian cancer. Clin Transl Oncol. 2015;17:956-61.

8. Karam A, Ledermann JA, Kim JW, Sehouli J, Lu K, Gourley C, et al. Fifth ovarian cancer consensus conference of the Gynecologic Cancer InterGroup: first-line interventions. Ann Oncol. 2017:28:711-7.

9. Du Bois A, Marth C, Pfisterer J, Harter P, Hilpert F, Zeimet AG, et al. Neoadjuvant chemotherapy cannot be regarded as adequate routine therapy strategy of advanced ovarian cancer. Int J Gynecol Cancer. 2012;22:182-5.

10. Oza AM, Cook AD, Pfisterer J, Embleton A, Ledermann JA, Pujade-Lauraine E, et al. Standard chemotherapy with or without bevacizumab for women with newly diagnosed ovarian cancer (ICON7): overall survival results of a phase 3 randomised trial. Lancet Oncol. 2015;16:928-36.

11. Mirza MR, Monk BJ, Herrstedt J, Oza AM, Mahner S, Redondo A, et al. Niraparib maintenance therapy in platinum-sensitive, recurrent ovarian cancer. N Engl J Med. 2016;375:2154-64.

12. Santaballa A, Barretina P, Casado A, García Y, González-Martín A Guerra E, et al. SEOM Clinical Guideline in ovarian cancer (2016). Clin Transl Oncol 2016; 18: 1206-12.

13. Siegel RL, Miller KD, Jemal A. Cancer statistics, 2018. CA Cancer J Clin. 2018;68:7-30.

14. Cannistra SA. Cancer of the ovary. N Engl J Med. 2004;351:2519-29.

15. Rosen B, Laframboise S, Ferguson S, Dodge J, Bernardini M, Murphy J, et al. The impacts of neoadjuvant chemotherapy and of debulking surgery on survival from advanced ovarian cancer. Gynecol Oncol. 2014;134:462-7.

16. Elattar A, Bryant A, Winter-Roach BA, Hatem M, Naik R. Optimal primary surgical treatment for advanced epithelial ovarian cancer. Cochrane Database Syst Rev. 2011;8:CD007565.

17. May T, Comeau R, Sun $\mathrm{P}$, Kotsopoulos J, Narod SA, Rosen B, Ghatage P. A comparison of survival outcomes in advanced serous ovarian cancer patients treated with primary debulking surgery versus neoadjuvant chemotherapy. Int J Gynecol Cancer. 2017;27:668-74.

18. Chiva L, Lapuente F, Castellanos T, Alonso S, Gonzalez-Martin A. What should we expect after a complete cytoreduction at the time of interval or primary debulking surgery in advanced ovarian cancer? Ann Surg Oncol. 2016:23:1666-73.

19. Pujade-Lauraine E, Ledermann JA, Selle F, Gebski V, Penson RT, Oza AM, et al. Olaparib tablets as maintenance therapy in patients with platinum-sensitive, relapsed ovarian cancer and a BRCA-1/2 mutation (SOLO2/ENGOT-Ov21): a double-blind, randomised, placebo-controlled, phase 3 trial. Lancet Oncol. 2017;18:1274-84.

20. Mariappan $L$, Jiang $X Y$, Jackson J, Drew $Y$. Emerging treatment options for ovarian cancer: focus on rucaparib. Int J Womens Health. 2017;9:913-24. 